\title{
Patterns of industrial specialisation in post-Unification Italy*
}

\author{
Carlo Ciccarelli ${ }^{\dagger}$ \\ SEFEMEQ, University of Rome "Tor Vergata" \\ Tommaso Proietti \\ SEFEMEQ, University of Rome "Tor Vergata"
}

This version: April 20, 2011

\begin{abstract}
This paper investigates the patterns of sectoral specialisation in Italian provinces over half a century following the Unification of the country. To this end we propose a multivariate graphical technique named dynamic specialisation biplots. In 1871 specialisation vocations toward the different manufacturing sectors were limited in size and no clear geographical path emerged. A regional specialisation divide resulted clearly in 1911. In 1871 as in 1911 the foodstuffs, the textile, and the engineering sectors represented the three pillars delimiting the arena of the specialisation race. Within that arena, sharp changes in the directions of specialisation trajectories characterise a group of selected Northern provinces, largely attracted by the textile sector from the 1880s and from the engineering sector in the pre-War decade. Within region homogeneity and smooth specialisation trajectories are instead representative of most of the remaining provinces. Among them, Southern provinces exhibit specialisation paths revealing that little more than a composition effect occurred among manufacturing sectors.
\end{abstract}

Keywords: manufacturing industry, specialisation, post-Unification Italy.

${ }^{*}$ Helpful comments on an earlier version of this paper were received from the participants at the 2011 annual conference of the Economic History Society, and at the Economic History Seminars of the Bank of Italy. Stefano Fenoaltea is kindly acknowledged for fruitful discussions. The usual disclaimer applies.

${ }^{\dagger}$ Address for Correspondence: SEFEMEQ, Facoltà di Economia, Università di Roma "Tor Vergata", Via Columbia 2, 00133 Roma, Italy. E-mail: carlo.ciccarelli@uniroma2.it 


\section{Introduction}

Modern economic growth has been illustrated deeply by economic historians. One of its distinctive feature is the shift to more durable products that occurred within manufacturing along the path to industrialisation (Kuznets, 1966). The distinction between durable and non-durable goods has proved to be also important in understanding the fluctuations of the Italian economy from Unification to the eve of World War One (Fenoaltea, 2003a). The same distinction, as this paper aims to show, proves to be important also to illustrate the evolution of industrial specialisation at the local level.

A recent contribution provided a new set of provincial industrial value added estimates for the years 1871, 1881, 1901, and 1911 (Ciccarelli and Fenoaltea, 2010). ${ }^{1}$ The focus of the authors was on industrialisation, investigated by looking at the relation between industrial growth and overall growth (as proxied by the growth of male labor force). On the one hand it was there confirmed that industrial growth was neither necessary nor sufficient for overall growth. Some established results were on the other hand subverted: while the analysis at the regional level pointed to a diffusion of industry, the new provincial estimates suggested a process of intensification, especially in the provinces of the northwestern triangle.

This paper uses the above mentioned estimates to take a closer look within industry and proposes a sectoral analysis of provincial specialisation in postUnification Italy. After a quick review of the structure of the manufacturing industry, the analysis focuses on provincial specialisation. We first use the standard biplot analysis to investigate provincial specialisation patterns at end-point benchmarks (1871 and 1911). We then extend our analysis to a dynamic setting and propose the dynamic specialisation biplot as a convenient tool to consider the evolution of provincial specialisation trajectories over time. A final section summarises the main findings.

\section{The structure of industrial production}

A recent work has carefully quantified the aggregate output and sectoral composition of post-Unification Italy's industry (Fenoaltea 2003a, pp. 710-712). Table 1 provides the main quantitative features for selected census years with up to date figures. Cols. 1-4 present the sectoral industrial value added shares, cols. 5-7 the related intercensual growth rates; cols. 8-11 finally present the sectoral concentra-

\footnotetext{
${ }^{1}$ The interested reader will find in Ciccarelli and Fenoaltea (2010) the genealogy of the mentioned estimates.
} 
tion index. ${ }^{2}$ The industrial activity of post-Unification Italy, as measured by total value added at 1911 prices, almost tripled. Three of its four components (mining, construction, and manufacturing) did almost as well, while its last major group (the utilities) exhibited a grand ten-fold increase. This noticeable growth ("at a two percent annual growth rate a capital doubles in 35 years", as the adage goes) was especially pronounced in the pre-War decade. ${ }^{3}$

The sectoral structure of industry at the national level is also briefly recalled. Within the four major groups, mining (Table 1, row 1) included a traditional export-led ore extraction activity (dominated by sulphur production) and a domestic component (including low-quality quarry products) tied to the construction sector. The latter was in turn closely related to the international Kuznets-cycle. ${ }^{4}$ As the sector's shares reveals, mining grew faster than average only in the first decade; even the construction's boom impulse of the "golden age" (about 19001911) partly reached the mining sector, whose last period growth was much mitigated by the sulphur crises, when Lousiana's sulphur mines overtake Sicily as the principal source of world supply. The utilities grew constantly faster than average, while the remaining major group (manufacturing as a whole) roughly kept its own share, although, and perhaps surprisingly, with a declining share in the very last decade.

Within the manufacturing group much of the initial value added was absorbed by sectors related to traditional activities tied to consumption (Table 1, roughly sectors 2.01 to 2.06 ) with modern sectors tied to investment (Table 1, roughly sectors 2.07 to 2.12) played, with few exceptions, a minor role. Over time, the traditional sectors generally lost shares for the benefit of the modern fast-growing ones. The loss was particularly evident in the last decade (Table 1, col. 11) when some manufacturing sectors (foodstuffs, tobacco, textiles, clothing, wood) grew less, or even considerably less (leather) than the average; as is not surprising, other modern sectors (engineering, sundry manufacturing) grew more or even considerably more (metalmaking, non metallic mineral products, chemicals and rubber, paper and printing) than the national average. ${ }^{5}$

\footnotetext{
${ }^{2}$ Value added estimates underlying Table 1 are from Ciccarelli and Fenoaltea (2010), Appendix Tables A1-A4.

${ }^{3}$ Ciccarelli and Fenoaltea (2007) provides a statistical test of structural break for the Italian GDP growth rate, enlarging the list of contributions to the apparently endless Gerschenkronian "take-off" debate.

${ }^{4}$ Fenoaltea (1988).

${ }^{5}$ Discriminating between "traditional" and "modern" sectors on the base of their "ex-post" growth rates is rather unsatisfactory, and this is especially so given the coarse sectoral disaggregation available at the provincial level. During the period at hand, to give one example, within the textile industry, "cotton boomed, hemp and linen fell even in absolute terms" (Fenoaltea (2004), pp. 149-150). The alternative distinction based on the production of durable and non-durable goods is, of course, more economically sound. It may be worth recalling that, while the cycle
} 
Table 1: Industrial sectors, census years

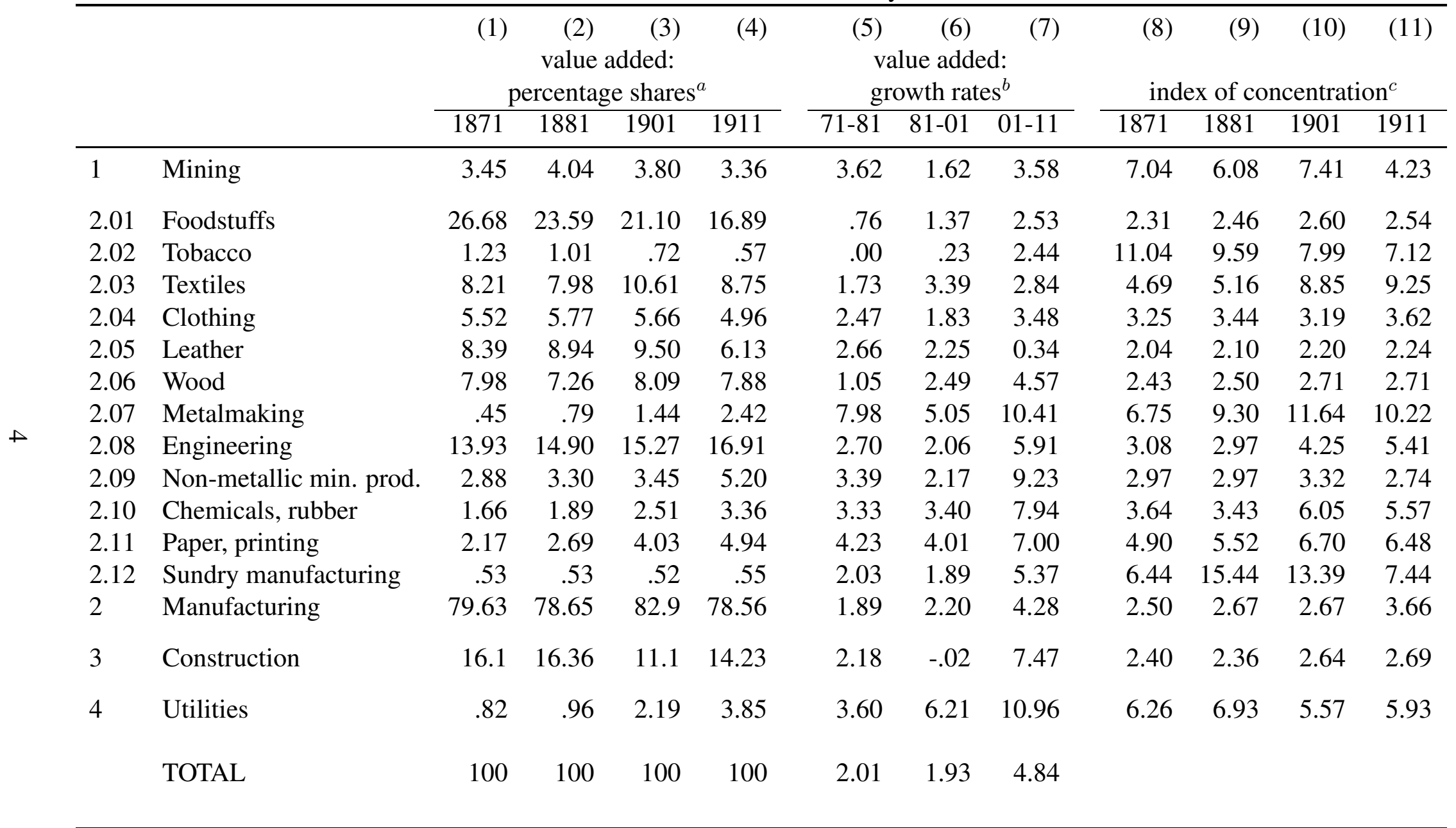

${ }^{a}$ numbers need not to add, due to rounding; ${ }^{b}$ growth rates $(\times 100)$ are on annual basis. ${ }^{c}$ Index of concentration $\times 100$. Total value added (rounded) figures, million lire at 1911 prices: 1705.1 (year 1871), 2081.1 (year 1881), 3052.3 (year 1901), 4897.2 (year 1911).

Source: See text. 
Cols. 8-11 of Table 1 present the sectoral concentration index for benchmark years. ${ }^{6}$ At the major-group level, mining is, as expected, always highly concentrated (the provincial allocation of Italy's mineral resources doesn't change much over time); the utilities, with the increasing spread of gas and electricity to minor urban centers, show declining figures over time; finally, construction and especially total manufacturing appear as quite diffused.

Traditional manufacturing activities (especially foodstuffs, leather, and wood) appear as constantly much diffused, showing to be almost indifferent to the falling transportation costs induced by the development of the railways. Similarly, the manufacture of non-metallic mineral products, with kilns placed in any place where bricks and tile were needed, spreads over the country. The tobacco industry appears, unsurprisingly, among the most concentrated. ${ }^{7}$

Modern manufacturing activities (metalmaking and, mostly markedly, engineering and chemicals) appears concentrated, and especially so after the turn of the century; coherently with the shift from traditional-silk to modern-cotton, a "turn of the century-effect" is also present in the textile sector.

Over the long run (1871 to 1911), traditional sectors experienced declining value added shares especially pronounced during the marked industrial development of the Giolittian decade; their degree of concentration was broadly constant. As a mirror image high-tech sectors showed a tendency to both increasing value added shares and concentration particularly pronounced during the upswing of the 1900-1911 period.

\section{Provincial specialisation in 1871 and 1911}

The provincial "data" used in this paper refer to the estimates of value added at 1911 prices and to the manufacturing sectors indicated in Table 1. For any census year $(1871,1881,1901,1911)$ the provincial figures were obtained by allocating

of durable goods did one entire revolution during the 1880 s, and it is thus completely missed by the 1881 and 1901 benchmarks, the rapid growth of the first decade of the new century, due in the main to the production of durables, was interrupted by the War. The "take-off" of the first decade, or the half revolution of the durables cycle, is duly accounted for by the 1901 and 1911 benchmarks.

${ }^{6}$ The concentration index is described in the Appendix A.

${ }^{7}$ The State has been the main actor of the tobacco business since the very beginning of its story. The public monopoly of production, import and sale of tobacco had been established in 1862 . Prices, quantities and-what is here relevant-place of production (more often than not a former monastery), were fixed by the law. In 1911, tobacco products were manufactured in Bari, Bologna, Cagliari, Catania, Chiaravalle, Florence, Lecce, Lucca, Milan, Modena, Naples, Palermo, Rome, Sestri, Turin, and Venice. Vetritto (2005) provides a fine long-term picture of the Italian tobacco industry. 
estimated regional sector-specific industrial value added figures with provincial sector-specific labor force census data. ${ }^{8}$

In order to describe empirically provincial specialisation patterns within manufacturing, a few standard notation, borrowed from Appendix A, can be conveniently introduced at this point. At any given point in time, industrial value added (million lire at 1911 prices) of province $i=1,2, \ldots, 69$, in sector $j=$ $1,2, \ldots, 12$, is denoted with $Y_{i j}$, and the related weight is given by $w_{i j}=Y_{i j} / \sum_{i} \sum_{j} Y_{i j}$. Summing over $i$ and $j$ marginal totals for sectors and provinces are obtained: $w_{. j}=\sum_{i} w_{i j}$ and $w_{i .}=\sum_{j} w_{i j} .{ }^{9}$ The specialisation coefficient is then given by

$$
s_{i j}=\frac{w_{i j}}{w_{i .}}-w_{. j}
$$

By further summing over sectors a measure $S_{i}=\sum_{j} s_{i j}^{2}$ of specialisation at the provincial level is readily obtained. Figure 1 illustrates its increase during the forty years here considered. ${ }^{10}$ In the long run the mean value almost doubles, increasing from .0165 in 1871 to .032 in 1911. A few provinces -Bergamo (BG), Como (CO), and Massa Carrara (MS), with its famous white marble quarries exploited all along - appear constantly as outliers. ${ }^{11}$

Overall provincial specialisation is only partly informative. When one moves the focus on sectoral specialisation, things became altogether more complicated to deal with. For a given point in time, with 69 provinces and 12 sectors, the specialisation matrix $S$ collects 828 coefficients. In such a situation specialisation biplots, ordinary biplots applied to specialisation data, reveal themselves to be

\footnotetext{
${ }^{8}$ Fenoaltea (2003b) used the very same method, at an higher geographical level, to obtain the first homogeneous diachronic estimates for the industrial value added of the 16 Italian regions, for the same census years considered here. The regional estimates there obtained were referred by the author as the 'first generation estimates'. Regional value added annual time series for the 18611913 period (the 'second generation estimates') for the mining, the construction, and the utilities industries have been recently provided by Ciccarelli and Fenoaltea (2009a); a second complementary volume, including the metalmaking, the engineering, the non-metallic mineral products, and the chemical sector is in press; a third and concluding volume, with the remaining manufacturing sectors, is in nuce. First and second generation estimates need no to coincide. First generation estimates use census-based sector-specific labor force as proxies of regional production, second generation estimates, with all the caveats of the case, measure production directly by reconstructing, product by product, year by year, the regional production of each industrial sector.

${ }^{9}$ The calculated values of $w_{. j}$, representing the national figures at census years, are those in Table 1, cols 1-4, duly scaled to include only manufacturing.

${ }^{10}$ In Figure 1 the specialisation data are graphically depicted by means of standard box plots. At any point in time, the height of the black box is given by the interquartile range (the difference between the third and first quartile), and the white line cutting the box represents the median value. Labeled points represent outliers, placed far away in the right tail of the distribution.

${ }^{11}$ It may worth recalling that the production of marble belongs to the extractive industry, while marble cutting and carving belongs to the non metallic mineral products sector. Only the second activity is considered in this paper.
} 
Figure 1: Provincial specialisation, at census years

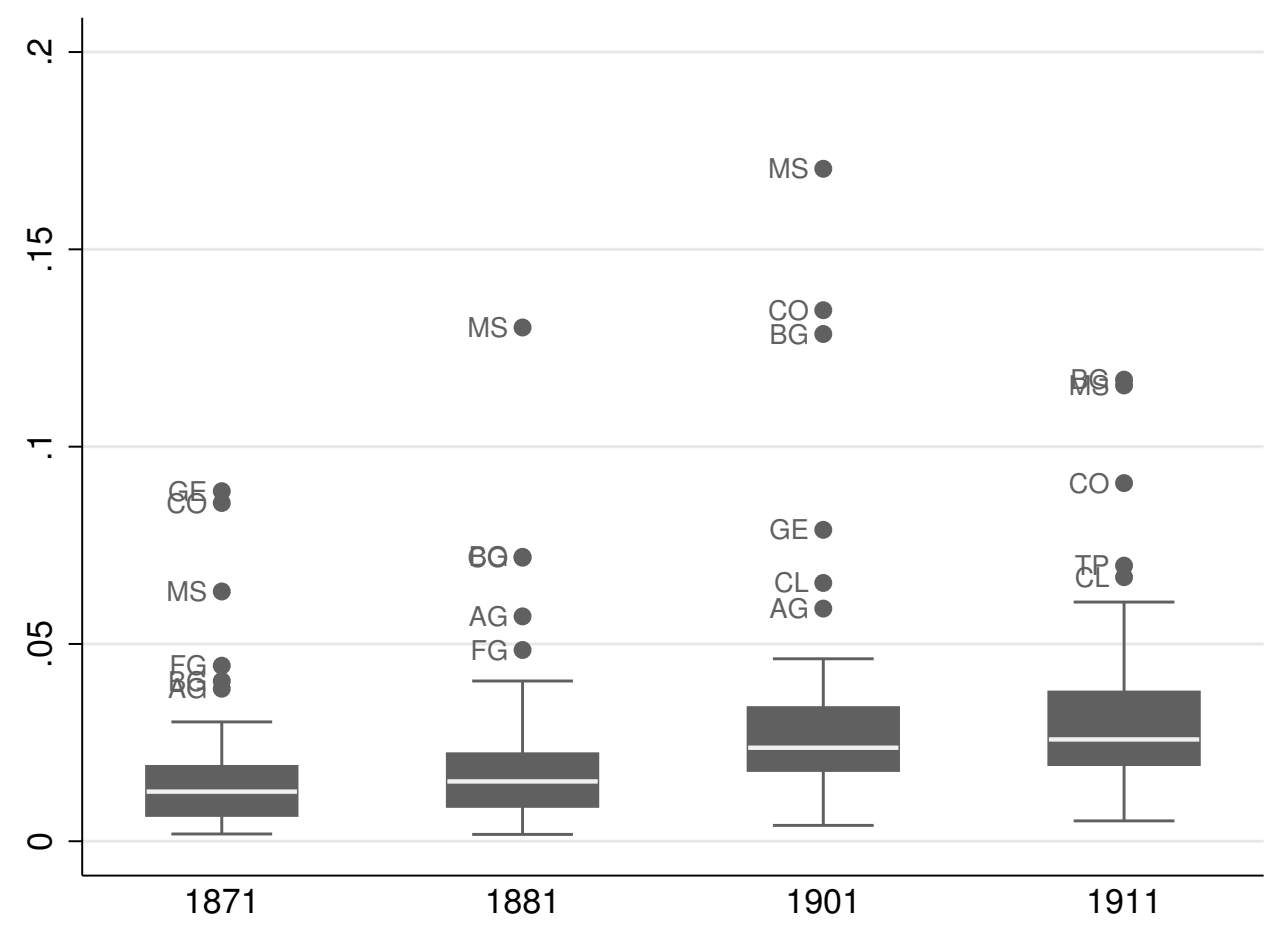

Source: see text.

very powerful statistical tools. In abstract terms, biplots are graphical devices providing information on both the rows (provinces) and the columns (sectors) of our data matrix $(S)$ in a simple two-dimensional representation, so that can be thought as the multivariate analogue of ordinary scatter plots. ${ }^{12}$

Figure 2, represents the specialisation of provinces in the manufacturing sectors in $1871 .^{13}$ The two dimensions (the horizontal and vertical side of the box) represent the first and the second component here derived from standard principal components analysis (PCA).

Labeled axes represent sectors. By construction, they intersect at the origin, where no specialization occurs. The position of the axis labels determines the sign of specialisation (labels belonging to the same side of the box share thus something in terms of specialisation). The numbers along each axis further determine the magnitude of specialization. The (lack of) distance between axes approximates the correlation between sectors: the closer the directions the higher the correlation; the sign of the correlation is indicated by axes labels, which give

\footnotetext{
${ }^{12}$ The formulas underlying specialisation biplots are presented in Appendix B.

${ }^{13}$ Appendix $\mathrm{C}$ provides a geographical map of Italian provinces.
} 
the sense of each axis. Interestingly, engineering, then dominated by traditional blacksmiths, appears to be correlated with the manufacturing of cloth; similarly, the chemicals sector of the time appears to be correlated with the manufacturing of wood, leather, and foodstuffs. ${ }^{14}$

Figure 2: Specialisation biplot, 1871

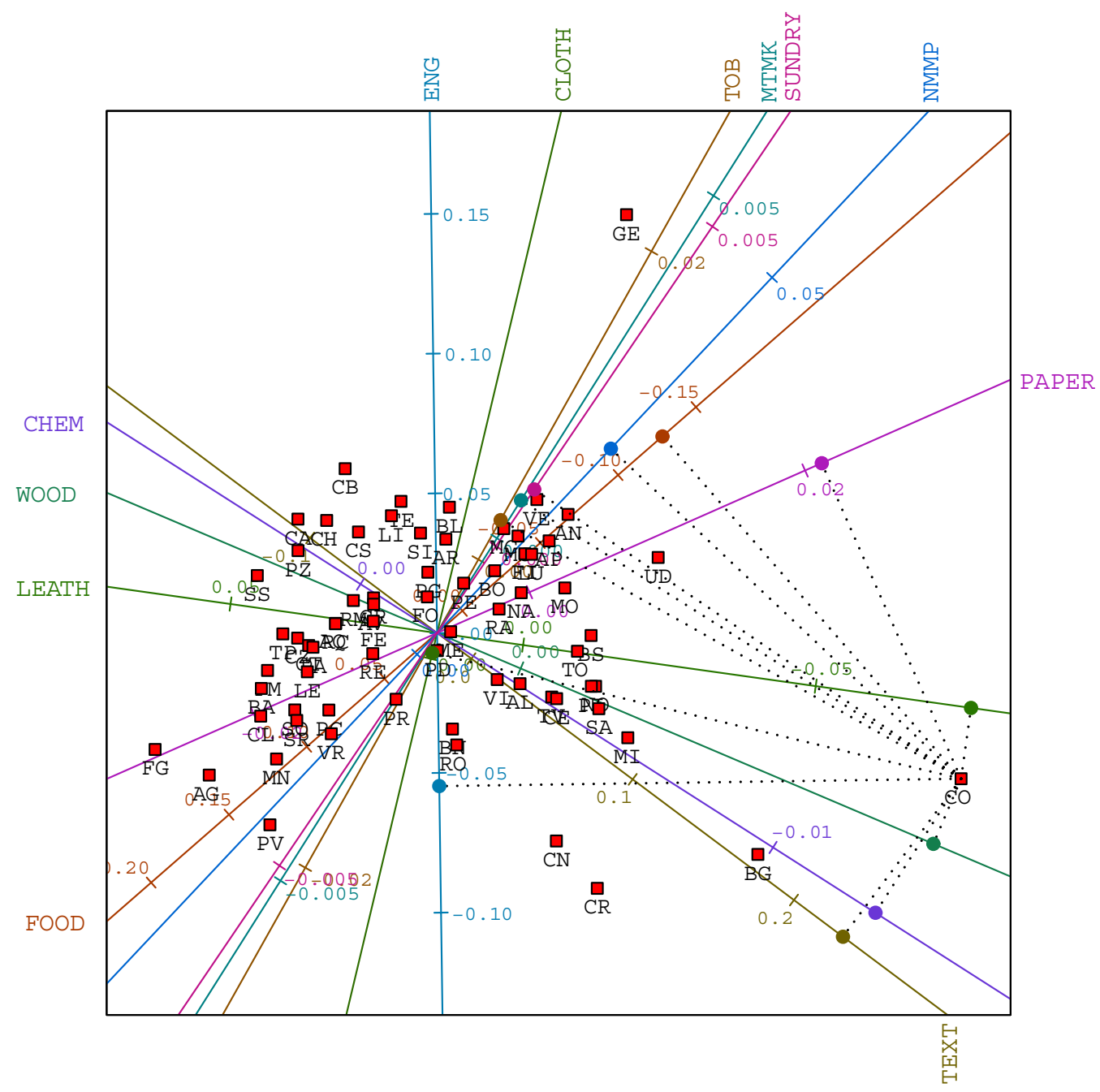

Source: See text.

Labeled points represent provinces ("scores", in the biplot jargon). The orthogonal projections of points on axes give the quantitative information on province

\footnotetext{
${ }^{14}$ In 1871 the chemicals industry was largely dominated by traditional activities. The production of matches, fats, oil, coloring materials, and pharmaceutical products accounted for almost 90 percent of total value added (Ciccarelli and Fenoaltea (2008), Table 5).
} 
specialisation, according to the prediction of the (PCA) model. An example, limited to the province of Como (CO), may help in illustrating the point. In 1871, the textile value added weight $\left(w_{i j} / w_{i}\right.$. ) for the case at hand is estimated to be (about) 0.36. The corresponding weight at the national level $w_{. j}$, estimated from the figures reported in Table 1, is about 0.10 . The positive difference $s_{i j}$ (roughly equal to 0.26 ), confirms that Como was highly specialized in textile production. The orthogonal projection of the point corresponding to Como (see the southeast zone of Figure 2) onto the textile axes represents the prediction according to the model $\left(\hat{s}_{i j}\right.$, roughly equal to 0.23$)$.

The 1871 specialisation biplot resembles the Japanese naval "rising sun" flag, with many of the provinces clustering within a little "red disc". On the one hand, the fact that the bulk of the points is rather uniformly distributed around the mean in a circular way reflects the different provincial orientation toward sectorial specialisation; on the other hand, the closeness of provinces around the mean signals moderate specialisation. Very few outstanding points are identified; they surely include Genoa (GE), the queen of early engineering; Como (CO), and Bergamo (BG) appear to be prominent textile provinces; at a lower level, Cuneo (CN) and Cremona (CR) score particularly high in the textile-foodstuff area. A mix of southern and northern provinces -Foggia (FG), Agrigento (AG), Pavia (PV) and Mantua (MN) - score particularly high in the foodstuff sector. Important industrial provinces- at least by the end of the period standards- do not stand out. Within region heterogeneity seems the prevailing rule. The example of Lombardy is illuminating. The region includes provinces belonging to the traditional area (Mantua (MN), Pavia (PV)) the modern area (Brescia (BS), Milan (MI), Bergamo (BG), Como (CO)) and the "in-between" area (Cremona (CR)). Political regions, and a fortiori macro-regions such as the North and the South, seem to be categories of little help in searching for local specialisation patterns at the beginning of the $1870 \mathrm{~s}$.

Figure 3 presents the specialisation biplot for 1911. The 1871 clustering around the center has disappeared and the sectors' grouping has also changed nicely. Traditional sectors tied to consumption (now including clothing) are on the left side of the box, while modern sectors tied to investment (now including the manufacturing of chemical products) lie on the bottom of the box. The by then mechanized textile sector is, as in 1871, separately identified, and tend to attract provinces on the north-east side of the box.

At the end of the period here considered, provinces emerging from the mass are typically located in the North: they range from the rural area of the Po valley - Mantua (MN), Pavia (PV), Cremona (CR) - to some subalpine provinces Bergamo (BG) and Como (CO) - with the exact position depending on the relative weight of the foodstuffs and textile sectors. Going clockwise one finds, as expected, the provinces forming the core of the "industrial triangle- - Milan (MI), 
Turin (TO), and Genoa (GE) - with the exact position depending on the relative weight of the textile and metalmaking-to-engineering sectors. Southern provinces tend to cluster on the left side of the biplot and are aligned along the foodstuffs axis, ranging from Trapani (TP) and Caltanissetta (CL) to Naples (NA), the leading industrial city of the South. While within regional heterogeneity is thus largely confirmed, a North-South specialisation divide has clearly emerged in 1911.

Figure 3: Specialisation biplot, 1911

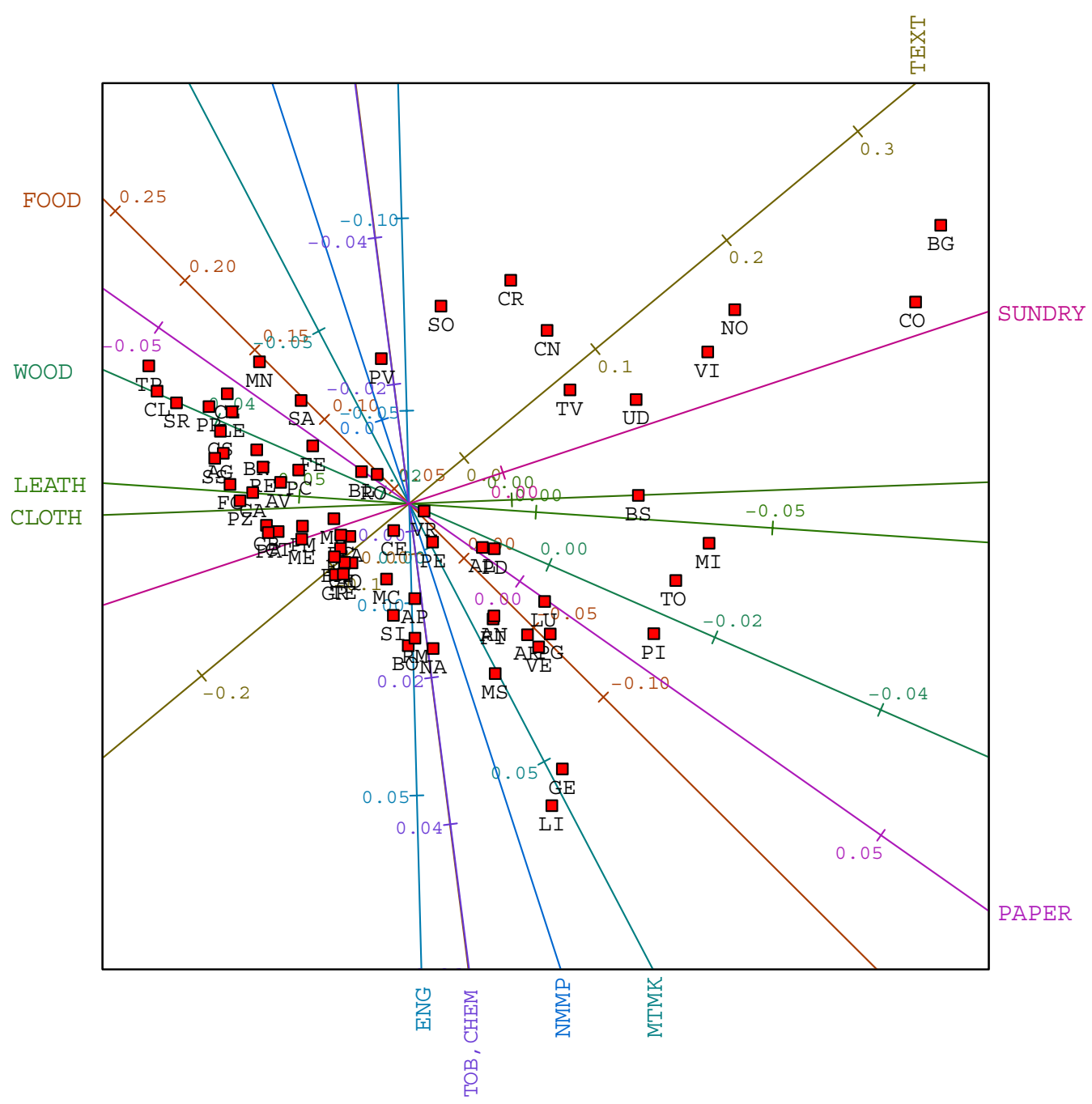

Source: See text.

Figures 2 and 3 presented the specialisation patterns predicted by the (PCA) model, as represented by the biplot graphical tools. As in the more familiar re- 
gression framework the estimated residuals - the difference between actual $\left(s_{i j}\right)$ and predicted $\left(\hat{s}_{i j}\right)$ specialisation coefficients - generate an uncountable number of alternative diagnostics and quality of fit measures. Table 2 presents the selected ones.

Table 2: Measures of statistical adequacy: 1871 and 1911

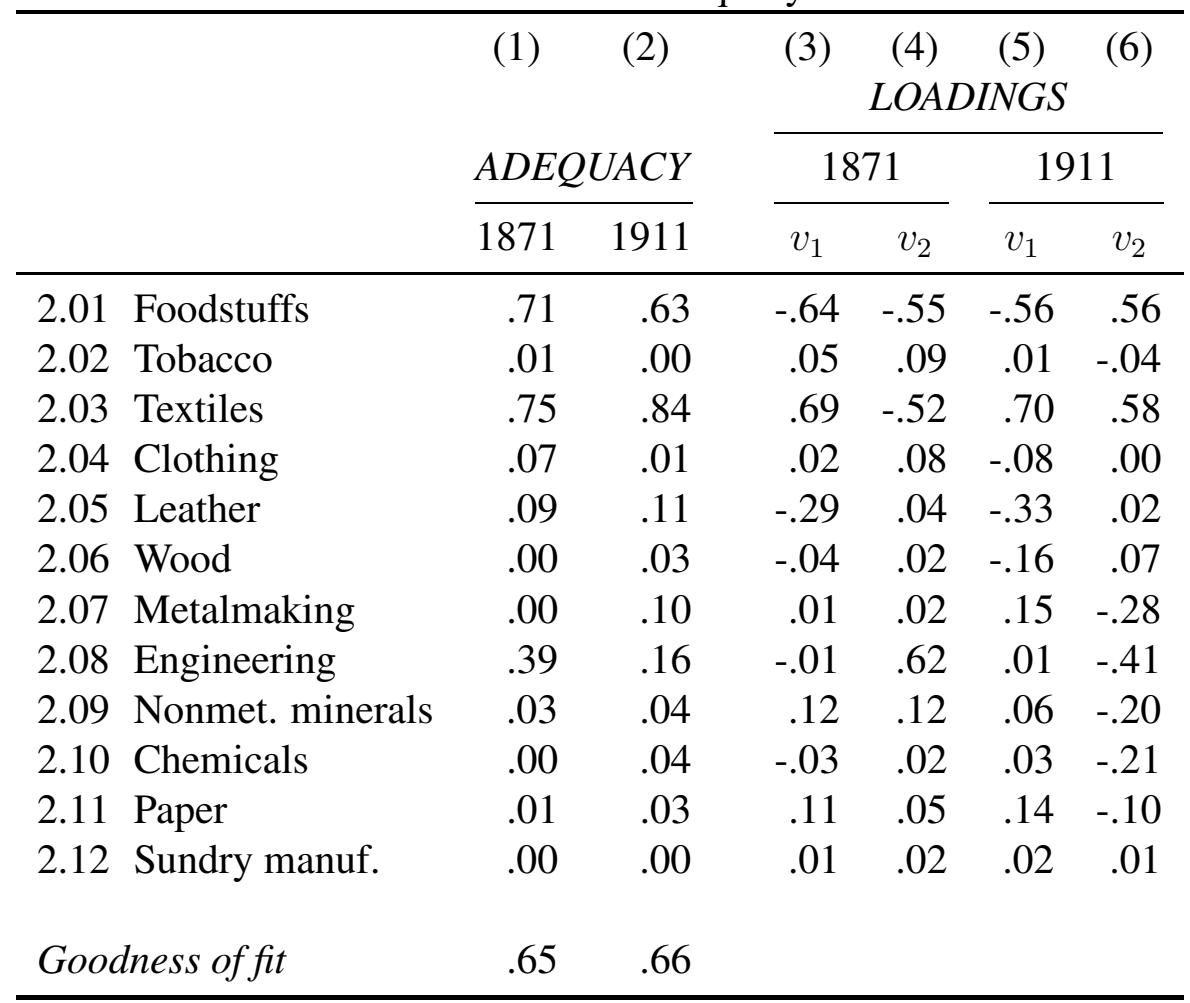

Source: See text.

In both years the overall goodness of fit measure, constrained to be in the $[0,1]$ range, is fairly high: about $65 \%$ of the variation in the samples is accounted for by the first-two principal components. Cols. 1-2 present sector specific diagnostics, with big number representing good approximation. Cols. 3-6 report the weights $v_{i t}$, with $i=1,2$ and $t=1871,1911$. These are the loadings obtained with the principal component analysis technique. At any time $t$, the adequacy measure of sector $j$ reported in cols. $1-2$ is defined as $A_{j}=v_{1 j}^{2}+v_{2 j}^{2} \cdot{ }^{15}$

While over the half-century at hand there was a generalized shift from an early artisanal way of producing to the modern factory system, the best represented

\footnotetext{
${ }^{15}$ For any sector $j$ the ratio $v_{2} / v_{1}$ gives the slope of the axis reported in Figures 2 and 3. Appendix $\mathrm{B}$ provides additional details.
} 
sectors appear to be in 1871 as in 1911 the foodstuffs, the textiles, and the engineering, followed, at a lower level, by leather, clothing and the manufacturing of non-metallic minerals: the remaining sectors are relatively poorly represented. ${ }^{16}$ On these bases, each of the presented biplot can ideally be partitioned into three convex areas. The first area-identified in 1911 by angles ranging from about 150 to about 270 degrees- includes sectors from foodstuff to engineering and can be thought as the "traditional sectors" zone. The second area-identified in 1911 by the angle ranging from about 270 to about 60 degrees- runs from engineering to textile and can be thought as the "modern sectors" area. Finally, the last areaidentified in 1911 by angles ranging from about 60 to about 150 degree, concluding so one revolution- includes provinces mainly specialised in the foodstuff and textile production.

Much like the land, the sea, and the air form the Mercedes-Benz three-pointed star logo, the foodstuffs, the engineering, and the textile sectors appear as the three pillars of the Italian manufacturing industry of the time. See again, from this perspective, Figures 2 and 3. These three sectors act as "sufficient statistics" for the whole industry and prove able to capture much of the provincial specialisation story of post-Unification Italy.

\section{Provincial specialisation over time}

The empirical evidence presented so far referred to end-point benchmark years (1871 and 1911). This section considers the evolution of provincial specialisation over time. In order to do so we extend the biplot framework to a dynamic setting in which sequences of specialisation matrices are available. We first define the specialisation matrix $\bar{S}=\left\{S_{1871}\left|S_{1881}\right| S_{1901} \mid S_{1911}\right\}$, obtained by stacking the four specialisation matrices referring to the individual census year (where $\mid$ represents vertical concatenation) ${ }^{17}$.

We then apply principal components analysis (PCA) to $\bar{S}$. Table 3 presents the main results in terms of statistical adequacy and loading matrices, which are much in line with those presented in Table 2: the best represented manufacturing sectors, are confirmed to be the textiles, the foodstuffs, and the engineering.

The main novelty of the proposed approach consists in defining, for each province $i$, a specialisation trajectory as the time-ordered sequences of its PCA-

\footnotetext{
${ }^{16}$ As a due consequence, big numbers appears, in order of magnitude, along the axes of the best represented sectors. So while, say, in 1871 Foggia (FG) is highly specialised in the foodstuffs sector, Udine (UD) is not particularly specialised in the paper sector (see Figure 2).

${ }^{17}$ The matrix $\bar{S}$ has thus 276 rows and 12 columns. The columns refer to the sectors, whereas rows 1-69 refer to the provinces in 1871; rows 70 to 138,139 to 207 , and 208 to 276 store the same information for the years 1881, 1901, and 1911.
} 
Table 3: Measures of statistical adequacy: 1871-1911

\begin{tabular}{|c|c|c|c|}
\hline & (1) & (2) & (3) \\
\hline & \multirow[b]{2}{*}{$A D E Q U A C Y$} & \multicolumn{2}{|c|}{$L O A D I N G S$} \\
\hline & & $v_{1}$ & $v_{2}$ \\
\hline 2.01 Foodstuffs & 0.76 & -0.62 & 0.61 \\
\hline 2.02 Tobacco & 0.00 & 0.02 & -0.06 \\
\hline 2.03 Textiles & 0.82 & 0.67 & 0.61 \\
\hline 2.04 Clothing & 0.01 & -0.03 & -0.07 \\
\hline 2.05 Leather & 0.11 & -0.33 & -0.07 \\
\hline 2.06 Wood & 0.01 & -0.08 & -0.05 \\
\hline 2.07 Metalmaking & 0.02 & 0.09 & -0.12 \\
\hline 2.08 Engineering & 0.14 & -0.02 & -0.38 \\
\hline 2.09 Nonmet. minerals & 0.08 & 0.14 & -0.24 \\
\hline 2.10 Chemicals & 0.02 & 0.02 & -0.12 \\
\hline 2.11 Paper & 0.03 & 0.13 & -0.11 \\
\hline 2.12 Sundry manuf. & 0.00 & 0.02 & -0.02 \\
\hline Goodness of fit & .66 & & \\
\hline
\end{tabular}

Source: See text.

scores: $s t_{i}=\left\{g_{i, 1871}, g_{i, 1882}, g_{i, 1901}, g_{i, 1911}\right\}$. Their graphical representation is readily obtained by linearly connecting the provincial scores at subsequent points (scores) in time. Figure 4 presents the results, collected by political regions: we refer to the proposed graphical tool as to the dynamic specialisation biplot. ${ }^{18}$

The axes, related to the first two principal components, are not region- or province-specific and are the same across the different regional boxes. The first biplot dimension (the horizontal axis) is more related to manufacturing sectors which experienced monotonic increases of their value added share in the four census years $(1871,1881,1901,1911)$. On the contrary, the second biplot dimension is more related to specialisation in shrinking traditional sectors, tied to consumption.

Provincial scores are represented with alphanumeric tags: the terms " $\mathrm{to}_{1}$, $\mathrm{to}_{2}$, to $_{3}$, and to ${ }_{4}$ " within the regional box referring to Piedmont represent, for instance, the scores $g$ of Turin in 1871, 1881, 1901, and 1911).

Even a rapid glance to regional panels reveals two essential features. The first is that specialisation trajectories are typically oriented towards the bottom of the

\footnotetext{
${ }^{18}$ Appendix B provides the technical details of the case.
} 
box, representing the general tendency to "modernity" (i.e. the drifting away from traditional sectors). ${ }^{19}$ The second essential feature is that within region heterogeneity of specialisation trajectories characterizes only northern regions. For the remaining regions, with the noticeable exception of the important textile province of Pisa in the panel for Tuscany, within region homogeneity appears as the prevailing rule. This much confirm and qualify in terms of specialisation trajectories the result presented in Ciccarelli and Fenoaltea (2010), that industrialisation was largely a sub-regional phenomenon.

A time-interval analysis is also informative. Specialisation trajectories can be ideally decomposed into three separate segments representing each a time interval (1871-1880, 1881-1900, and 1901-1911). The average length of the considered intervals, as measured by the Euclidean distance of subsequent provincial scores, increased from a value of .050 in the 1871-1881 subperiod, to .053 in 1881-1901, to end up with a 0.62 value in the last 1901-1911 interval, confirming, even in the "specialisation metric" the exceptionality of the Giolittian age. ${ }^{20}$

The segments illustrating the 1871-1881 interval, as noticed, are of relatively reduced length, reflecting little change in the average provincial vocation toward different manufacturing sectors. From this respect, the often mentioned extension from Piedmont to the rest of the country of the existing mild tariff, occurred soon after the 1861 Unification may seem to be either negligible or, at least, ineffective after 1871. This conclusion would be not fully appropriate however. More than the average length, the directions of the specialisation trajectories seem to matter for the case at hand; and those emerging from Campania are illuminating. The majority of provinces within Campania (Salerno (SA), Caserta (CE), and Naples (NA)) started their specialisation race from a point pretty close to that of modern industrial provinces, at least by the end-of-the-story standards, such as Turin and Milan. $^{21}$ Between 1871 and 1881 the southern provinces here considered chose the "wrong" direction: Salerno and Caserta followed a "west-first-then-south" specialisation-trajectory while, to keep the comparison consistent, Turin and Milan followed an "east-first-then-south". Part of the story may be related to the sudden reduced role of the textile sector in Campania and, on the opposite, to the increased role played by the same sector in Piedmont and Lombardy. Whether

\footnotetext{
${ }^{19}$ As is often the case rule admit exceptions: the specialisation trajectory representing Parma points to the foodstuffs sector between the second and third census year; the one representing Trapani points to the foodstuffs sector between the third and fourth census years.

${ }^{20} \mathrm{~A}$ local disaggregation of the above mentioned figures for the pre-War decade reveals that above average length of specialisation trajectories $(0.075)$ characterized the northern regions of Piedmont, Liguria, Lombardy, and Venetia; below average length (0.051) characterized instead the southern regions (from Abruzzi to Sardinia). Regions belonging to the center of Italy were characterized by roughly average length.

${ }^{21}$ The scores representing Salerno and Campania within Figure 2 appear very close to those representing Turin and Milan.
} 
the diverging trajectories can be fully accounted for by only considering the textile sector is hard to say. What more generally emerges from the specialisation analysis considered so far is that Campania was not a member of the "Southern club" since the beginning of the specialisation race, but rather joined the club itself after a counterclockwise evolution occurred in the first intercensal period. This evolution appears, to the present writers, a possible result of the effect of the reduced protectionism induced by the mentioned extension of the mild tariff from Piedmont to the rest of the country occurred soon after the Unification.

The segments referring to the 1881-1901 and 1901-1911 intervals are also of particular interest. Between the end of the 1870s and of the 1880s Italy embraced protectionism. New duties resulted in a higher degree of protection of the textile sector. ${ }^{22}$ In Italy, as early elsewhere, industrialisation began with the traditional production of textiles by means of water-powered machine, registered a growing importance of steam-powered machines used to produce consumption goods (such as the protected cotton), and reached quite soon the production-ofmachines-by-means-of-machines-phase of the pre-War decade, the golden-age of the engineering sector.

Figure 4 reveals that the previous story dovetails nicely with selected provinces of the North. An "east-first-then-south" dynamic path surely characterizes two famous industrial provinces such as Milan (MI), and Turin (TO). Genoa (GE), the last vertex of the industrial triangle, was steadily involved in the heavy metalmaking and engineering activities. ${ }^{23}$ Similar specialisation trajectories emerge for Bergamo (BG), Como (CO), Novara (NO), Vicenza (VC), and Treviso (TV) in the North, and Pisa (PI) in Tuscany. ${ }^{24}$ To a great extent the leading industrial regions (Piedmont, Liguria, and Lombardy) were characterized by a balanced regional mix of their provinces' vocation towards specialisation.

Specialisation trajectories of the remaining regions share, as partly noticed, many common features. First, while within the northern regions heterogeneous trajectories were the rule, the regional biplots from Emilia to Sardinia, typically

\footnotetext{
${ }^{22}$ The debate on protectionism among contemporary historians seem to be not yet concluded. A partial list of primary references includes Toniolo (1990), pp. 82-84, Zamagni (1993) pp. 110-117, Cohen and Fedrico (2001), pp. 64-65, and Fenoaltea (2011), chapter 4. Felice (2007) summarises the different points of view on State intervention and the origin and development of the regional divide.

${ }^{23}$ The enduring high-tech vocation of Genoa dates at least back to 1871 ; its non-monotonic path, is largely due the ship-building crisis of the 1870s, documented in Ciccarelli can Fenoaltea (2009b). The mandatory reading on the industrial development of Genoa between the 1815 and the 1914 is Doria (1969-1973).

${ }^{24}$ The "industrial districts" of Biellese, Vicentino, Novarese, Varesotto, Brianza, Cremasco, Val Trompia, Val Brembana are the examples of little Manchesters, by Italian standards, considered in Cafagna (1999). The latter work includes a comprehensive review of the literature on the industrial and economic development of Northern Italy.
} 
very crowded and with provincial trajectories hardly disentangled, point to a regional more than a provincial specialisation story. Secondly, many (mostly Southern) provinces start their specialisation race from the foodstuff starting grid. Thirdly, the trajectories unfold smoothly and point "to the south" rather directly, reflecting by and large a composition effect of industrial sectors at an higher (national) level.

To summarise, the evolution of specialisation over time considered so far pointed to a sub-regional specialisation story for selected regions. They surely include Piedmont, Liguria and Lombardy, but also Venetia and to some degree Tuscany. For the remaining regions, surely including the southern regions, the specialisation story can in the main be told at the regional level and reveals little more than that a long term decrease in the value added share of traditional sectors to the advantage of modern sectors aligned on the bottom side of the dynamic biplots occurred.

\section{Conclusions}

This paper considered provincial specialisation patterns in post-Unification Italy.

In 1871 specialisation vocations toward the different manufacturing sectors were limited in size and no clear geographical path emerged. A regional specialisation divide emerged clearly in 1911 instead: virtually only Northern provinces spread out of the mass; the three provinces forming the core of the industrial triangle (Turin, Milan and, above all, Genoa) appear specialised in modern sectors tied to the production of durable goods. The remaining provinces appear as mainly specialised in traditional sectors, tied to the production of consumption goods.

In 1871 as in 1911 the foodstuffs, textile, and engineering sectors represented the three pillars delimiting the arena of the specialisation race. Within that arena the provincial specialisation trajectories were further considered. A regional divide clearly emerged. Sharp change in their directions are typical of selected Northern provinces largely attracted by the textile sector from the 1880s and from the engineering sector in the last pre-War decade. Within region homogeneity characterized instead the smooth specialisation trajectories of most of the remaining provinces. Among them, Southern provinces exhibit specialisation paths revealing little more than that a composition effect occurred among manufacturing sectors. 
Figure 4: Dynamic specialisation biplots, 1871-1911
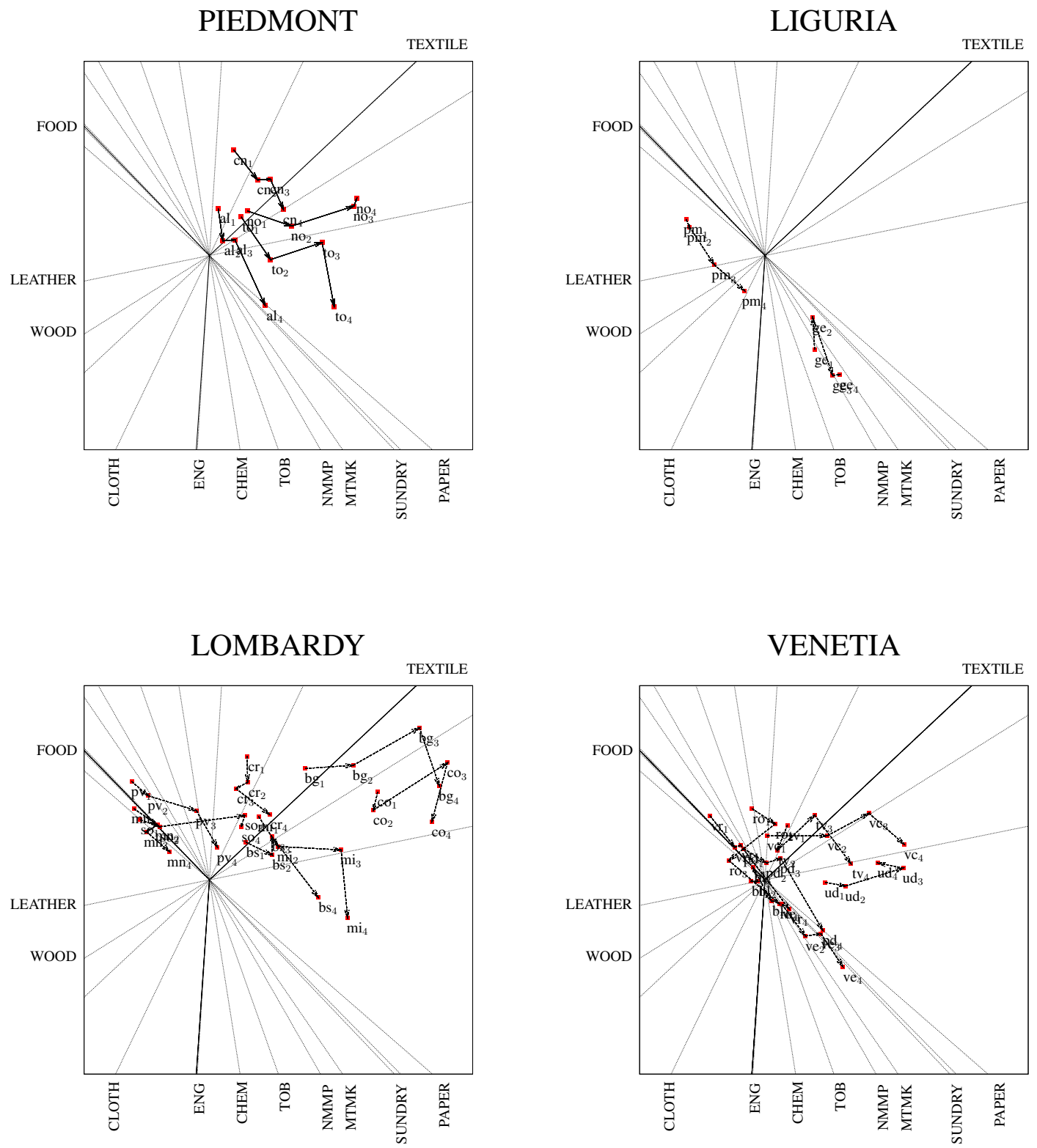
Figure 4, cont.
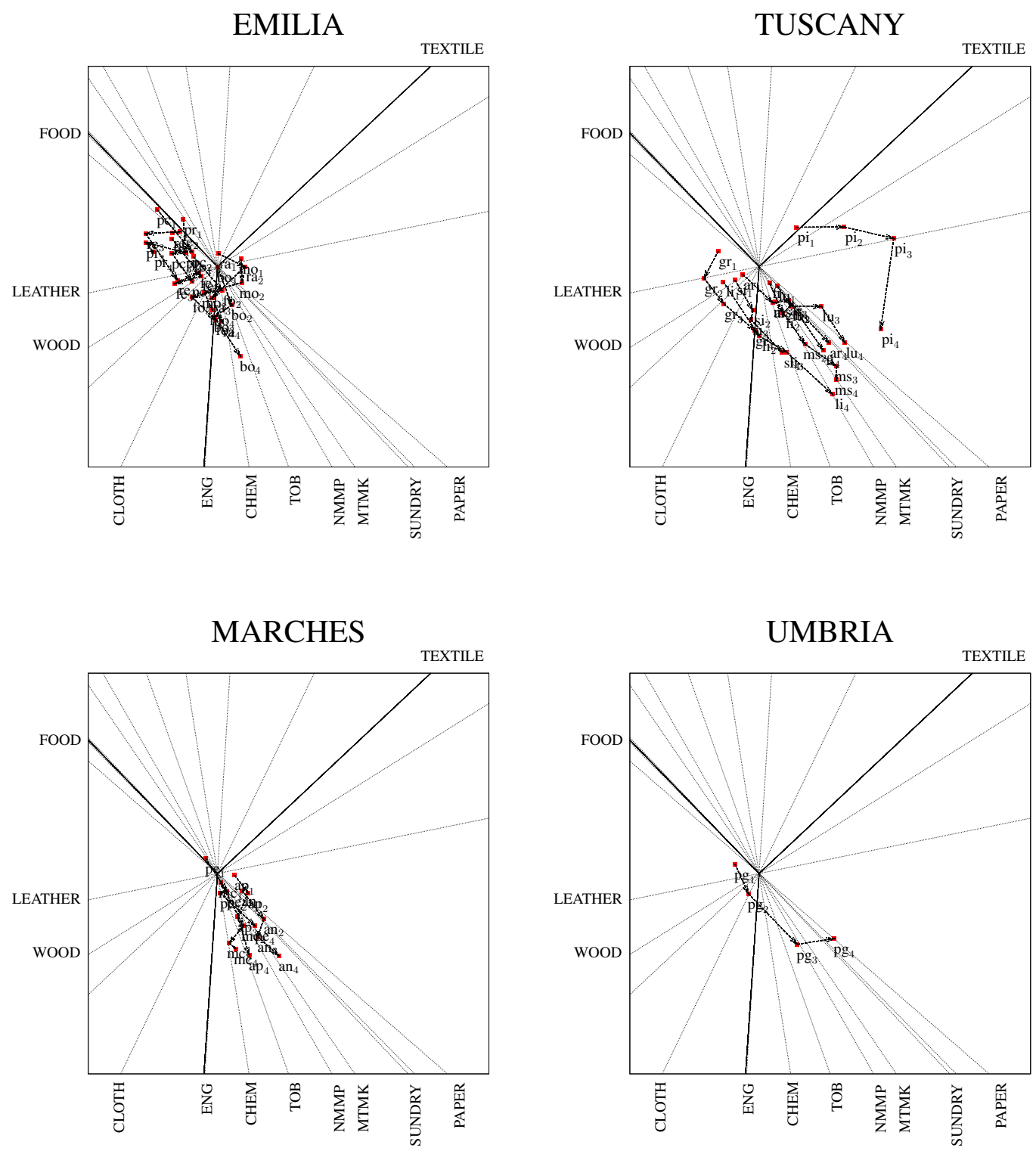
Figure 4, cont.
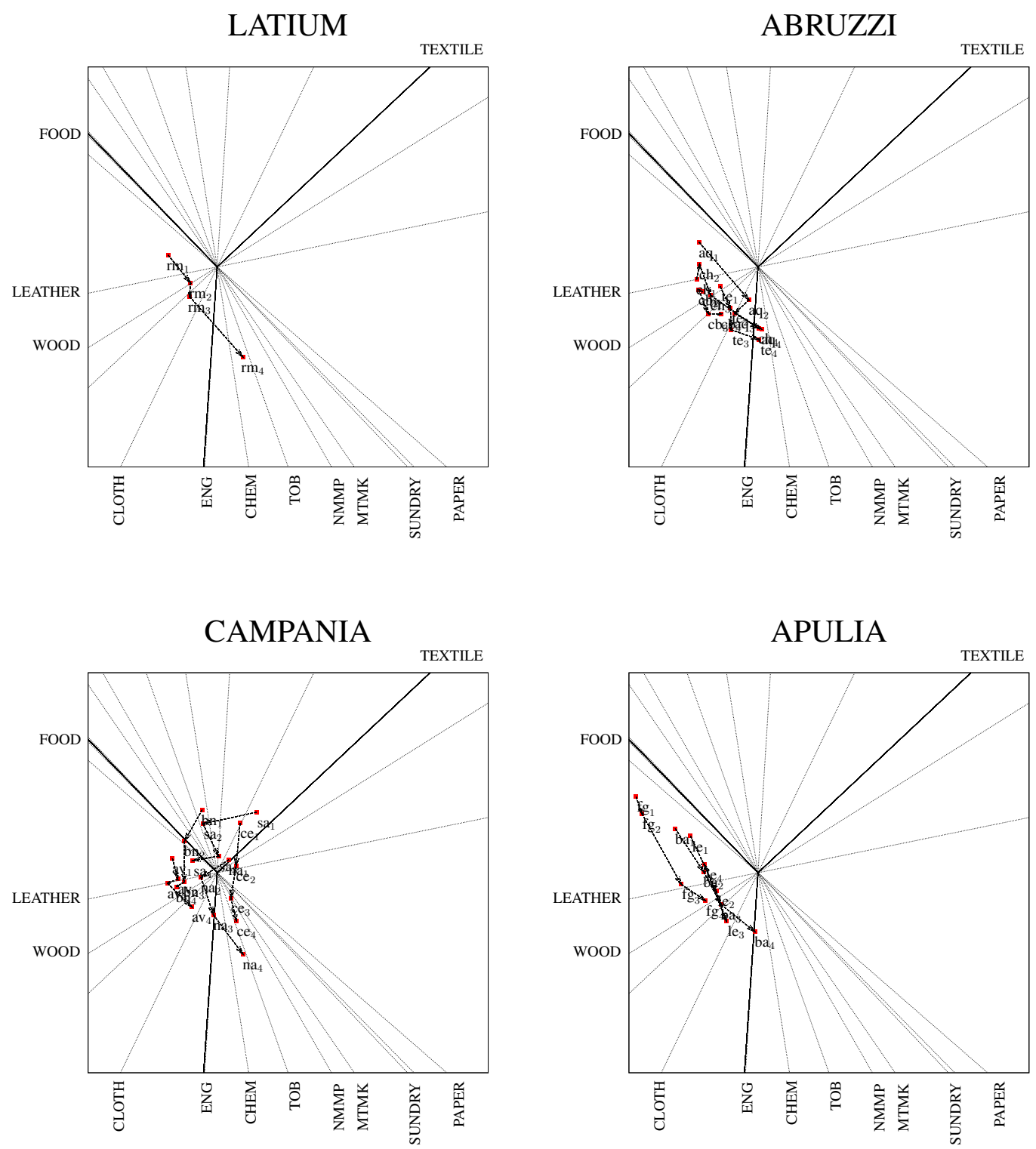
Figure 4, cont.
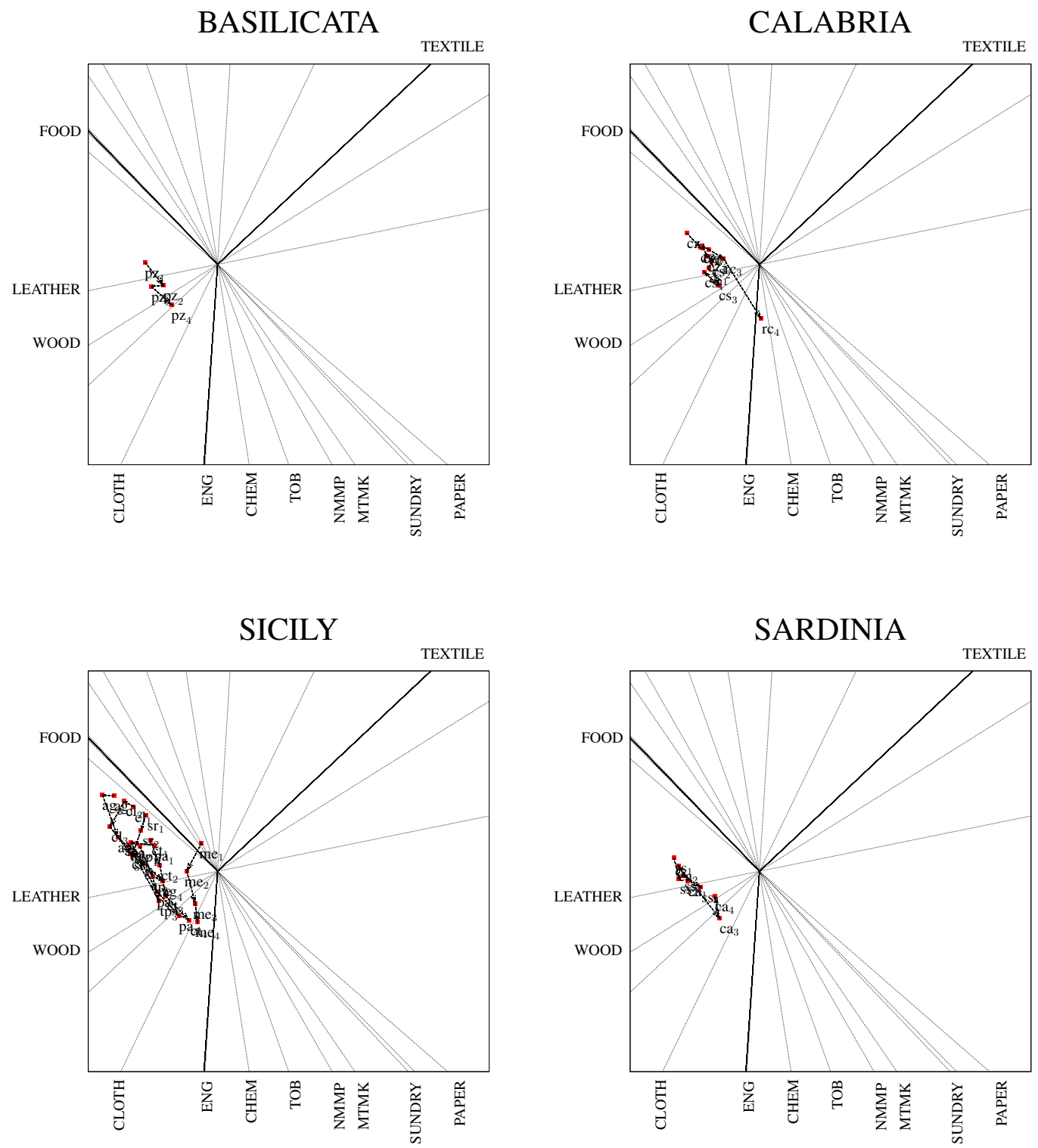

Source: see text. 


\section{A Specialisation and concentration indices}

Our data set consists of value added for $I=69$ provinces, disaggregated into $J=12$ manufacturing sectors and $T=4$ time units, the census years (1871, $1881,1901,1911)$. The value added of sector $s$ in province $i$ at time $t$ is denoted

$$
Y_{i j, t}, i=1, \ldots, I, j=1, \ldots, J, t=1, \ldots, T
$$

The data are organised in an array of $T$ matrices each of dimension $I \times J, \boldsymbol{Y}_{t}, t=$ $1, \ldots, T$.

Let us focus on a particular census year and let us drop the time index for simplicity of notation. Also, denote by $Y_{. j}=\sum_{i} Y_{i j}$ the total value added for sector $s$, by $Y_{i}=\sum_{j} Y_{i j}$ the total value added for the $i$-th province, by $Y_{. .}=$ $\sum_{i} \sum_{j} Y_{i j}$ the national total and let

$$
w_{i j}=\frac{Y_{i j}}{Y_{. .}}, \quad w_{i .}=\frac{Y_{i .}}{Y_{. .}}=\sum_{j} w_{i j}, \quad w_{. j}=\frac{Y_{. j}}{Y_{. .}}=\sum_{i} w_{i j} .
$$

The specialisation of province $i$ is defined in terms of the quantities

$$
s_{i j}=\frac{w_{i j}}{w_{i .}}-w_{. j}=\frac{Y_{i j}}{Y_{i .}}-\frac{Y_{. j}}{Y_{. .}} .
$$

In particular, province $r$ is specialised in sector $s$ if the value added share of sector $s$ in the province above the national sector share and vice-versa.

The $r$-th province specialisation coefficient is the variance of the sector specific coefficients $s_{i j}$ :

$$
S_{i}=\sum_{j=1}^{S} s_{i j}^{2}
$$

(As a matter of fact, $\sum_{j} s_{i j}=0$, i.e. the $s_{i j}$ have zero mean).

The measurement of sectoral concentration takes the sectors as the reference unit of the analysis: the assessment can be based on the quantities

$$
\xi_{i j}=\frac{w_{i j}}{w_{. j}}-w_{i .}=\frac{Y_{i j}}{Y_{. j}}-\frac{Y_{i .}}{Y_{. .}}
$$

We say that sector $s$ is concentrated in region $r$ if the value added share pertaining to province $r$ is larger than the overall weight of the province in the national economy.

Noticing that $\sum_{i} \xi_{i j}=0$, the sector $s$ concentration index can be based on the variance of the $\xi_{i j}$ :

$$
C_{j}=\sum_{i} \xi_{i j}^{2}
$$


However, it is more common to use the Herfindal index, which is defined as the quadratic mean of the shares $w_{i j} / w_{. j}$,

$$
H_{j}=\sum_{i}\left(\frac{w_{i j}}{w_{. j}}\right)^{2} .
$$

The Herfindal index ranges from $\sum_{i} w_{i}^{2}$ to 1 . The estimated values for the years 1871, 1881, 1901, and 1911 are reported in Table 1, cols. 8-11.

Specialisation and concentration are intimately related to localisation. A localisation coefficient compares the weight of sector $s$ in province $r$ with the marginal sectoral weights:

$$
q_{i j}=\frac{Y_{i j} / Y_{i .}}{Y_{. j} / Y_{. .}}=\frac{w_{i j}}{w_{i .} w_{. j}} .
$$

Values greater than one imply that the presence of a sector in a province is above average. This can be viewed as the ratio of $w_{i j}$ with the value expected under the hypothesis of independence of the value added share (in which case there is no specialisation and the Herfindal concentration index is constant for all sectors).

\section{B Biplots}

Biplots (Gower and Hand, 1996) are effective graphical displays that aim at summarising the information contained in a matrix. For instance, two-dimensional specialisation biplots are constructed from the best two-dimensional approximation of the data $\left\{s_{i j}, i=1, \ldots, I, J=1, \ldots, J\right\}$, in a two-dimensional space. The observed $s_{i j}$ is decomposed into two orthogonal components as follows:

$$
\begin{aligned}
& s_{i j}=\hat{s}_{i j}+e_{i j}, \\
& \hat{s}_{i j}=g_{i 1} v_{j 1}+g_{i 2} v_{j 2} .
\end{aligned}
$$

Here, $\hat{\varsigma}_{i j}$ is the best approximation obtained from interacting the vector $g_{i}=$ $\left[g_{i 1}, g_{i 2}\right]^{\prime}$, which is specific to the $i$-th province and distills its profile, with the vector $v_{j}=\left[v_{j 1}, v_{j 2}\right]^{\prime}$, which is specific of the sector $j$. The estimated values of $v_{j}$ are reported in Tables 2 and 3 . The component $e_{i j}$ is a residual term and it is orthogonal to $\hat{s}_{i j}$.

In other words, $g_{i}$ contains the coordinates of the province $i$ in the best approximating two-dimensional space defined by two latent variables that distill the most part of the information contained in the original dataset. The elements of the $v_{j}$ contain the weights that should be attached to the latent dimensions so as to approximate $s_{i j}$ with the highest accuracy. As a matter of fact, the optimality of the representation lies in the fact that, among the possible decomposition, $\sum_{i} \sum_{j} e_{i j}^{2}$ is small as possible. 
From the technical standpoint, the decomposition (1) is achieved by the singular value decomposition of a matrix (see Gower and Hand (1996) and Greenacre (2010) for an introduction). The decomposition is related to the multivariate method known as principal components analysis; the scores $g_{i}=\left[g_{i 1}, g_{i 2}\right]^{\prime}$ are obtained the principal component scores, i.e. the projection of the province profile on the space spanned by the two underlying principal components of the and the points $v_{j}$ are the loadings of the sectors on the principal components.

The interpretation of the specialisation biplot is such that $\hat{s}_{i j}$ is obtained from the orthogonal projection of the point $g_{i}$ on the vector $v_{i}$; provinces with similar specialisation profile are represented close in the graph. More specialised provinces are represented further away from the origin of the display.

The figures presented in section 3 were obtained using the BiplotGUI package, providing a graphical user interface for the $\mathrm{R}$ package. The package (described in la Grange et al. (2009)) allow the user to easily the kind of biplot advocated by Gower and Hand (1996), biplots in which samples are represented as points and variables are represented as calibrated axes.

The quality of the approximation can be assessed using the goodness of fit measure: $0 \leq \frac{\lambda_{1}+\lambda_{2}}{\sum_{k=1}^{J} \lambda} \leq 1$ where $\lambda_{1}$ and $\lambda_{2}$ are the largest eigenvalues of the matrix $\tilde{S}^{\prime} \tilde{S}$, where $S=\left\{s_{i j}\right\}$.

Dynamic biplots are obtained by the decomposition

$$
\varsigma_{r s, t}=\hat{\varsigma}_{r s, t}+e_{r s, t}, \hat{\varsigma}_{r s}=g_{r 1, t} v_{s 1, t}+g_{r 2, t} v_{s 2}
$$

where the row and column profile vectors $g_{r 1, t}, g_{r 2, t}$ and $v_{s 1}, v_{s 2}$ are obtained from the singular value decomposition of the matrix obtained from stacking the four specialisation coefficient matrices for the different census years.

\section{Italy's provinces}

The name of each region, in bold, is followed by the name (and tag) of its provinces.

PIEDMONT: Alessandria (AL), Cuneo (CN), Novara (NO), Turin (TO)

LIGURIA: Genoa (GE), Porto Maurizio (PM)

LOMBARDY: Bergamo (BG), Brescia (BS), Como (CO), Cremona (CR), Mantua (MN), Milan (MI), Pavia (PV), Sondrio (SO)

VENETIA: Belluno (BL), Padua (PD), Rovigo (RO), Treviso (TV), Udine (UD), Venice (VE), Verona (VR), Vicenza (VI)

EMILIA: Bologna (BO), Ferrara (FE), Forl (FO), Modena (MO), Parma (PR), Piacenza (PC), Ravenna(RA), Reggio Emilia (RE)

TUSCANY: Arezzo (AR), Florence (FI), Grosseto (GR), Leghorn (LI), Lucca 
(LU), Massa Carrara (MS), Pisa (PI), Siena (SI)

MARCHES: Ancona (AN), Ascoli Piceno (AP), Macerata (MC), Pesaro (PE)

UMBRIA: Perugia (PG)

LATIUM: Roma (RM)

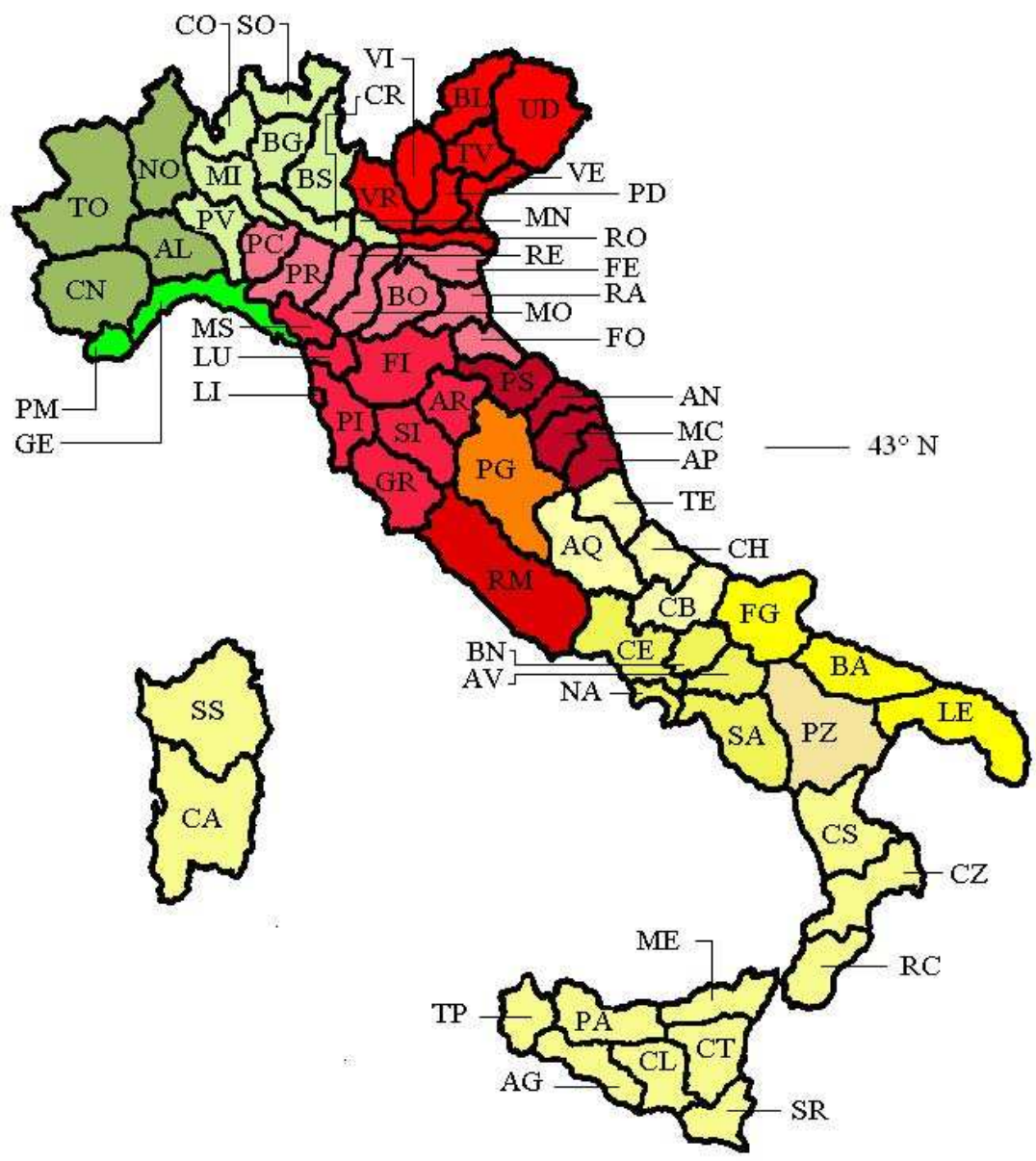

ABRUZZI: Aquila (AQ), Campobasso (CB), Chieti (CH), Teramo (TE)

CAMPANIA:Avellino (AV), Benevento (BN), Caserta (CE), Naples (NA), Salerno (SA)

APULIA: Bari (BA), Foggia (FG), Lecce (LE)

BASILICATA: Potenza (PZ)

CALABRIA: Catanzaro (CZ), Cosenza (CS), Reggio Calabria (RC)

SICILY: Caltanissetta (CL), Catania (CT), Girgenti (AG), Messina (ME), Palermo (PA), Syracuse (SR), Trapani (TP)

SARDINIA: Cagliari (CA), Sassari (SS) 


\section{References}

Cafagna L. (1999), "Contro tre pregiudizi sulla storia dello sviluppo economico italiano," in P. Ciocca and G. Toniolo, eds., Storia economica d'Italia, vol. 1: Interpretazioni, pp. 297-325, Laterza, Bari

Ciccarelli C. and Fenoaltea S. (2007), "Business Fluctuations in Italy, 1861-1913: The New Evidence," Explorations in Economic History XLIV, no. 3 (July 2007), pp. 432-451

Ciccarelli C. and Fenoaltea S. (2008), “The Chemical, Coal and Petroleum Products, and Rubber Industries in Italy's Regions, 1861-1913: Time Series Estimates," Banca d'Italia, Quaderni dell'Ufficio Ricerche Storiche, no. 16, May 2007; Rivista di storia economica, XXIV, no. 1 (aprile 2008), pp. 3-58

Ciccarelli C. and Fenoaltea S. (2009a), La produzione industriale delle regioni d'Italia, 1861-1913: una ricostruzione quantitativa. 1. Le industrie non manifatturiere, Banca d'Italia, Rome

Ciccarelli C. and Fenoaltea S. (2009b), "Shipbuilding in Italy, 1861 1913: the Burden of the Evidence," Historical Social Research 34, pp. 333-73.

Ciccarelli C. and Fenoaltea S. (2010), "Through The Magnifying Glass: Provincial Aspects of Industrial Growth In Post-Unification Italy," Banca d'Italia, Quaderni di Storia Economica (Economic History Working Papers), no. 4, July 2010

Cohen J. and Federico G. (2001), The Growth of the Italian Economy, 1820-1960, Cambridge University Press, Cambridge

Doria G. (1969-1973), Investimenti e sviluppo economico a Genova alla vigilia della Prima Guerra Mondiale Italian Economy, Università degli Studi di Genova - Giuffrè Editore, Genova

Felice E. (2007), Divari regionali e intervento pubblico. Per una rilettura dello sviluppo in Italia, Il Mulino, Bologna

Fenoaltea S. (1988), "International Resource Flows and Construction Movements in the Atlantic Economy: The Kuznets Cycle in Italy, 1861 1913," Journal of Economic History XLVIII, no. 3 (September 1988), pp. 605-638

Fenoaltea S. (2003a), "Notes on the Rate of Industrial Growth in Italy, 18611913," Journal of Economic History LXIII, no. 3 (September 2003), 695-735 
Fenoaltea S. (2003b), "Peeking Backward: Regional Aspects of Industrial Growth in Post-Unification Italy," Journal of Economic History LXIII, no. 4 (December 2003), pp. 1059-1102

Fenoaltea S. (2004), “Textile Production in Italy's regions, 1861-1913,” Rivista di storia economica XX, no. 2 (agosto 2004), pp. 145-174

Fenoaltea S. (2011), The Reinterpretation of Italian Economic History: From Unification to the Great War, Cambridge University Press, Cambridge.

Greenacre M. (2010), Biplots in Practice, Fundación BBVA, Bilbao

Gower J.C. and Hand D.J. (1996), Biplots, Monographs on Statistics and Applied Probability, Chapman \& Hall, London, UK

Kuznets S., Modern Economic Growth: Rate, Structure, and Spread, Yale University Press, New Haven, Connecticut

Lagrange A., le Roux N., and S. Gardner-Lubbe (2009), "BiplotGui: Interactive Biplots in R", Journal of statistical software, n. 12, pp. 1-37

Toniolo G. (1990), An Economic History of Liberal Italy, 1850-1918, Routledge, London and New York

Vetritto G. (2005), La parabola di un'industria di Stato. Il Monopolio dei tabacchi 1861-1997, Marsilio, Venezia

Zamagni V. (1993), The Economic History of Italy, 1860-1990, Clarendon Press, Oxford 